\title{
Sustained Drug-related Reaction With Eosinophilia and Systemic Symptoms (DRESS) Triggered by Low Molecular Weight Heparins in COVID-19: Management and Precision Diagnosis.
}

\section{Elena Minenna}

Medical and Surgical Sciences

Nada Chaoul

University of Bari Department of Emergency and Organ Transplantation, School and Chair of Allergology and Clinical Immunology

\section{Maria Pia Rossi}

University of Bari Department of Emergency and Organ Transplantation, School and Chair of Allergology and Clinical Immunology

\section{Lucia Giliberti}

University of Bari, Dept. of Emergency and Organ Transplantation, School and Chair of Allergology and Clinical Immunology

\section{Marcello Albanesi}

University of Bari, Dept. of Emergency and Organ Transplantation, School and Chair of Allergology and Clinical Immunology

\section{Eustachio Nettis}

University of Bari, Dept. of Emergency and Organ Transplantation, School and Chair of Allergology and Clinical Immunology

\section{Maria Pia Foschino Barbaro}

University of Foggia, Dept. of Clinical and Surgical Sciences

\section{Danilo Di Bona}

University of Bari, Dept. of Emergency and Organ Transplantation, School and Chair of Allergology and Clinical Immunology

\section{Maria Filomena Caiaffa}

University of Foggia, Dept of Clinical and Surgical Sciences

\section{Luigi Macchia ( $\square$ luigi.macchia@uniba.it)}

Dept. of Emergency and Organ Transplantatio, School and Chair of Allergology and Clinical Immunology, University of Bari https://orcid.org/0000-0002-5896-086X

\section{Case Report}


Keywords: Drug allergy, Precision medicine, Lymphocyte proliferation test, Anticoagulants, Dermatitis Posted Date: April 26th, 2021

DOI: https://doi.org/10.21203/rs.3.rs-439675/v1

License: (c) (1) This work is licensed under a Creative Commons Attribution 4.0 International License. Read Full License

Version of Record: A version of this preprint was published at Advances in Dermatology and Allergology on January 1st, 2021. See the published version at https://doi.org/10.5114/ada.2021.109586. 


\section{Abstract}

Background. Low molecular weight heparins (LMWHs) are administered routinely to COVID-19 patients. Systemic reactions to LMWHs (both IgE-mediated and non IgE-mediated) are considered rare. Particularly, a single case of drug-related reaction with eosinophilia and systemic symptoms (DRESS) due to enoxaparin has been described in the literature. Here, we report on the first case of DRESS related to administration of fondaparinux.

Case presentation. An elderly woman was diagnosed with COVID-19, during the "first wave" of the pandemics in Italy, and treated with enoxaparin (for anti-coagulation). A DRESS syndrome developed after two weeks (RegiSCAR score $=7$ ). Enoxaparin was considered the culprit drug and replaced with the fully synthetic LMWH fondaparinux. At the same time, high-dosage prednisone was added to the therapy. The DRESS slowly subsided and the patient survived. Upon recovery and corticosteroid washout, a lymphocyte proliferation test for both LMWHs was performed, yielding a positive response not only for enoxaparin but also for fondaparinux.

Conclusions. By lymphocyte proliferation test we demonstrated that both enoxaparin and fondaparinux were implicated in this case of DRESS, occurring in an elderly COVID-19 patient. In retrospect, the choice of using a sustained high-dose corticosteroid treatment while maintaining anti-coagulation by fondaparinux proved to be right. Ultimately, the patient recovered from both DRESS and COVID-19.

\section{Background}

Low molecular weight heparins (LMWHs), particularly enoxaparin, are administered routinely to COVID-19 patients, in order to treat or prevent the associated, possibly serious coagulation disorders. ${ }^{1}$

Both IgE-mediated and non IgE-mediated systemic reactions to LMWHs are considered rare. ${ }^{2-4}$ Particularly, a single case of drug-related reaction with eosinophilia and systemic symptoms (DRESS) has been documented in the literature. ${ }^{4}$

Here we report on an elderly COVID-19 patients who developed DRESS upon prophylactic treatment with enoxaparin. Etiological diagnosis was corroborated by lymphocyte proliferation test (LPT) ${ }^{5}$, upon recovery. The management strategy adopted is outlined and commented.

\section{Case Presentation}

A 95 year old female resident of a nursing home developed acute respiratory symptoms, at the peak of the COVID-19 "first wave" in Italy, in March 2020. Upon hospitalization, infection by SARS-COV2 was confirmed by nasopharyngeal swab, followed by PCR detection of the Corona virus. Chest computed tomography revealed diffuse bilateral infiltrates. At admission, blood counts were in the normal range (including eosinophils, $70 / \mathrm{ml}$ ), with elevated erythrocyte sedimentation rate $(87 \mathrm{~mm} / \mathrm{h}$ ) and C-reactive protein $(18.7 \mathrm{mg} / \mathrm{l})$ as the only abnormal laboratory values. Underlying comorbidities included type 2 
diabetes and hypertension (both moderate and well controlled). Upon hospitalization, she was treated (empirically) with hydroxychloroquine (400 mg/die) and enoxaparin (4,000 Ul/die). Her conditions remained fair for two weeks (with no need for oxygen therapy), when she presented with a maculopapular skin eruption with a pupuric aspect and scaling, involving more than $50 \%$ of the body surface (abdomen, back, upper and lower limbs), accompanied by severe pruritus and burning sensation. Fever (> $38.5^{\circ} \mathrm{C}$ ), lymph node swelling at multiple peripheral stations and elevated serum creatinine values completed the clinical picture. Withe blood cell count reached $15,160 / \mathrm{ml}$, with eosinophil count at 1,540/ml. A DRESS diagnosis was established (RegiSCAR score $=7$ ).${ }^{6}$ Thus, hydroxychloroquine, associated with severe drug hypersensitivity, including DRESS, ${ }^{7-10}$ was discontinued. Enoxaparin dosage was doubled (8,000 IU/die), in consideration of increased D-dimer values $(2.173 \mathrm{mg} / \mathrm{ml})$. Prednisone (25 $\mathrm{mg} / \mathrm{die})$ and cetirizine (10 $\mathrm{mg} / \mathrm{die}$ ) were added to the therapy. However, a further deterioration of the clinical conditions occurred, leading to replacement of enoxaparin with the fully synthetic pentasaccharyde factor Xa inhibitor fondaparinux ( $2.5 \mathrm{mg} /$ die, subcutaneously), generally well-tolerated in patients with local non-immediate cutaneous reactions to LMWHs, including enoxaparin. ${ }^{11,12}$

Management of the case according to this therapeutic schedule led to a slow resolution of maculopapular lesions, over approximately one month, with a substantial fever decline achieved in 2 weeks and apyrexia in 3 weeks. Finally, the eosinophil counts also declined steadily and normalized by day 30 after the emergence of the DRESS eruption. Prednisone and fondaparinux were then discontinued.

A few days later, the patient was discharged, upon double successive negative nasopharyngeal swab.

Precision diagnosis. Following a 7-day corticosteroid wash-up period, a blood sample was obtained from the patient (fully recovered; at home). Peripheral blood mononuclear cells were isolated by gradient centrifugation $\left(800 \times \mathrm{g}, 45^{\prime}\right)$ on Lympholyte ${ }^{\circledR}$ (Cedarlane, EuroClone, Milan, Italy), upon plasma removal and suspension of the blood cellular moiety in Dulbecco's phoshate buffered saline. Mononuclear cells were maintained in Dulbecco's modified Eagle's medium, with $10 \%$ autologous serum $(\mathrm{v} / \mathrm{v})$, with streptomycin $(100 \mathrm{mg} / \mathrm{ml})$, at $37{ }^{\circ} \mathrm{C}$, in a $5 \% \mathrm{CO}_{2}$, vapour-saturated atmosphere, in $64 \mathrm{~cm}^{2}$ glass Petri dishes, for 4 days, in order to allow clearance of the monocyte-macrophage component. Successively, micro-cultures were generated with the resulting purified lymphocytes $\left(6 \times 10^{4}\right.$ cells in $\left.200 \mathrm{ml}\right)$ and employed for carrying out LPT for enoxaparin and fondaparinux, respectively, under culturing conditions as above. LPT was performed essentially as described. ${ }^{13}$ Briefly, triplicate micro-cultures were incubated with the two drugs, respectively, at three different ten-fold concentrations: therapeutic concentration (TC; calculated on the drug distribution volume), TC/10 and TCx10 (defect and excess concentration, respectively). The distribution volume and the TC were $5.24 \mathrm{I}$ and $15 \mathrm{mg} / \mathrm{l}$, for enoxaparin, ${ }^{14}$ and $9 \mathrm{I}$ and $0.27 \mathrm{mg} / \mathrm{l}$ for fondaparinux. ${ }^{15}$ Triplicate micro-cultures incubated with phytohemagglutinin-M (from Phaseolus vulgaris; $2.25 \mathrm{mg} / \mathrm{ml}$ ) and the medium alone served as the positive and the negative control, respectively. Following 4-day incubation with the drugs, lymphocyte proliferation was assessed upon inclusion of the non-radioactive thymidine analogue 5-bromo-2'-deoxyuridine (BrdU; $100 \mathrm{mM}$ ), in the micro-cultures, for 2 hours. Incorporation of the nucleotide in proliferating cells was evaluated by an anti- 
BrdU monoclonal antibody (7.5 U/ml; from Roche Diagnostics GmbH, Mannheim, Germany). ${ }^{16,17}$ The LPT is deemed positive when the proliferation rate of any of the three concentrations tested compared to negative control (stimulation index) equals or exceeds 2. 5,13

The assay revealed that not only enoxaparin (as suspected) but also fondaparinux induced significant lymphocyte proliferation (Figure).

\section{Discussion And Conclusion}

LMWHs, including enoxaparin, have been involved mainly in local delayed hypersensitivity reactions. These reactions are not very infrequent and often mild or moderate. Fondaparinux appears to be tolerated by patients with previous delayed local reactions to LMWHs. ${ }^{9-12}$

Systemic severe delayed reactions, particularly DRESS, are more rare. To our knowledge, this is the second report of a DRESS associated to exposure to enoxaparin and the first one of DRESS associated to fondaparinux. Moreover, by LPT, we showed that the two LMWHs cross-reacted with each other, making fondaparinux an unlikely alternative to endoxaparin in the case of severe delayed systemic reactions (in spite of the fully synthetic structure).

Thus, a full blown DRESS occurred in an elderly COVID-19 patient (with important comorbidities). This led to discontinuation of the probably useless hydroxychloroquine administration, in fear of a possible causative role. Enoxaparin was then suspected and discontinued. A sustained high dosage corticosteroid treatment was undertaken and the patient eventually recovered from both COVID-19 and DRESS and survived. Probably correct was the choice of maintaining anti-coagulation by LMWHs. Enoxaparin was indeed replaced with fondaparinux, in the belief that the latter drug had a less allergenic profile. Although, in retrospect, LPT proved it wrong, anticoagulation was probably instrumental in obtaining the healing.

\section{Abbreviations}

LMWHs: low molecular weight heparins; COVID-19: Coronavirus disease 2019; DRESS: drug-related reaction with eosinophilia and systemic symptoms; LPT: lymphocyte proliferation test; TC: therapeutic concentration; BrdU: 5-bromo-2'-deoxyuridine.

\section{Declarations}

\section{Ethics approval and consent to participate}

Not applicable.

\section{Consent for publication}

Written informed consent was sought after and obtained from the patient for publication of this case report. The work was carried out in compliance with the Declaration of Helsinki. 
Availability of data and materials

The clinical and laboratory records, upon which this paper is based, may be made available to third parties on request.

\section{Competing interests}

The Authors declare that they have no conflicts of interest.

\section{Funding}

The Authors declare that this study was carried out with institutional resources only.

\section{Author Contributions}

E.M. managed the case, analysed the clinical data and wrote the draft; N.C. performed the lymphocyte proliferation assay and analysed the data with the help of M.P.R. and L.G; M.A., E.N., M.P.F.B., D.D.B. and M.F.C. provided critical reading of the manuscript; L.M. helped conceiving the study, finalized the manuscript and secured financial support.

\section{Aknowledgment}

Not applicable.

\section{References}

1. Tang N, Bai H, Chen X, Gong J, Li D, Sun Z. Anticoagulant treatment is associated with decreased mortality in severe coronavirus disease 2019 patients with coagulopathy. J Thromb Haemost. 2020;18:1094-9.

2. Harr T, Scherer K, Tsakiris DA, Bircher AJ. Immediate type hypersensitivity to low molecular weight heparins and tolerance of unfractionated heparin and fondaparinux. Allergy. 2006;61:787-8.

3. Cesana P, Scherer K, Bircher AJ. Immediate type hypersensitivity to heparins: two case reports and a review of the literature. Int Arch Allergy Immunol. 2016;171:285-9.

4. Ronceray S, Dinulescu M, Le Gall F, Polard E, Dupuy A, Adamski H. Enoxaparin-induced DRESS syndrome. Case Rep Dermatol. 2012;4:233-7.

5. Porebski G, Gschwend-Zawodniak A, Pichler WJ. In vitro diagnosis of T-cell mediated drug allergy. Clin Exp Allergy. 2011;41:461-70.

6. Kardaun SH, Sekula P, Valeyrie-Allanore L, Liss Y, Chu CY, Creamer D, et al. Drug reaction with eosinophilia and systemic symptoms (DRESS): an original multisystem adverse drug reaction. Results from the prospective RegiSCAR study. Br J Dermatol. 2013;169:1071-80.

7. Volpe A, Marchetta A, Caramaschi P, Biasi D, Bambara LM, Arcaro G. Hydroxychloroquine-induced DRESS syndrome. Clin Rheumatol. 2008;27:537-9. 
8. Dordal Culla MT, Herrera-Lasso Ragás V, Martí-Garrido J, Rodríguez Cumplido D, Vázquez-Revuelta P. Lleonart Bellfill R. Treating COVID-19: review of drug hypersensitivity reactions. J Investig Allergol Clin Immunol. 2020;30:385-99.

9. Gelincik A, Brockow K, Çelik GE, Doña I, Mayorga C, Romano A, et al. Diagnosis and management of the drug hypersensitivity reactions in Coronavirus disease 19: an EAACI Position Paper. Allergy. 2020;75:2775-93.

10. Castro Jiménez A, Navarrete Navarrete N, Gratacós Gómez AR, Florido López F. García Rodríguez R, Gómez Torrijos E. First case of DRESS syndrome caused by hydroxychloroquine with a positive patch test. Contact Dermatitis. 2021;84:50-1.

11. Schindewolf M, Scheuermann J, Kroll H, Garbaraviciene J, Hecking C, Marzi I, et al. Low allergenic potential with fondaparinux: results of a prospective investigation. Mayo Clin Proc. 2010;85:913-9.

12. Tan E, Thompson G, Ekstrom C, Lucas M. Non-immediate heparine and heparinoid cutaneous allergic reactions: a role for fondaparinux. Intern Med J. 2018;48:73-7.

13. Albanesi M, Di Girolamo A, Aresta V, Rossi MP, Giliberti L, Perrone T, et al. Delayed allergy to acyclovir revealed by lymphocyte proliferation test. Adv Dermatol Allergol. 2018;35:527-9.

14. Bruno R, Baille P, Retout S, Vivier N, Veyrat-Follet C, Sanderink G-J, et al. Population pharmacokinetics and pharmacodynamics of enoxaparine in unstable angina and non-ST-segment elevation myocardial infarction. Br J Clin Pharmacol. 2003;56:407-14.

15. Donat F, Duret JP, Santoni A, Cariou R, Necciari J, Magnani H, et al. The pharmacokinetics of fondaparinux sodium in healthy volunteers. Clin Pharmacokinet. 2002;41 Suppl:2:1-9.

16. Porstmann T, Ternynck T, Avrameas S. Quantitation of 5-bromo-2-deoxyuridine incorporation into DNA: an enzyme immunoassay for the assessment of the lymphoid cell proliferative response. $J$ Immunol Methods. 1985;82:169-79.

17. Heil J, Reifferscheid G. Detection of mammalian carcinogens with an immunological DNA synthesisinhibition test. Carcinogenesis. 1992;13:2389-94.

\section{Figures}



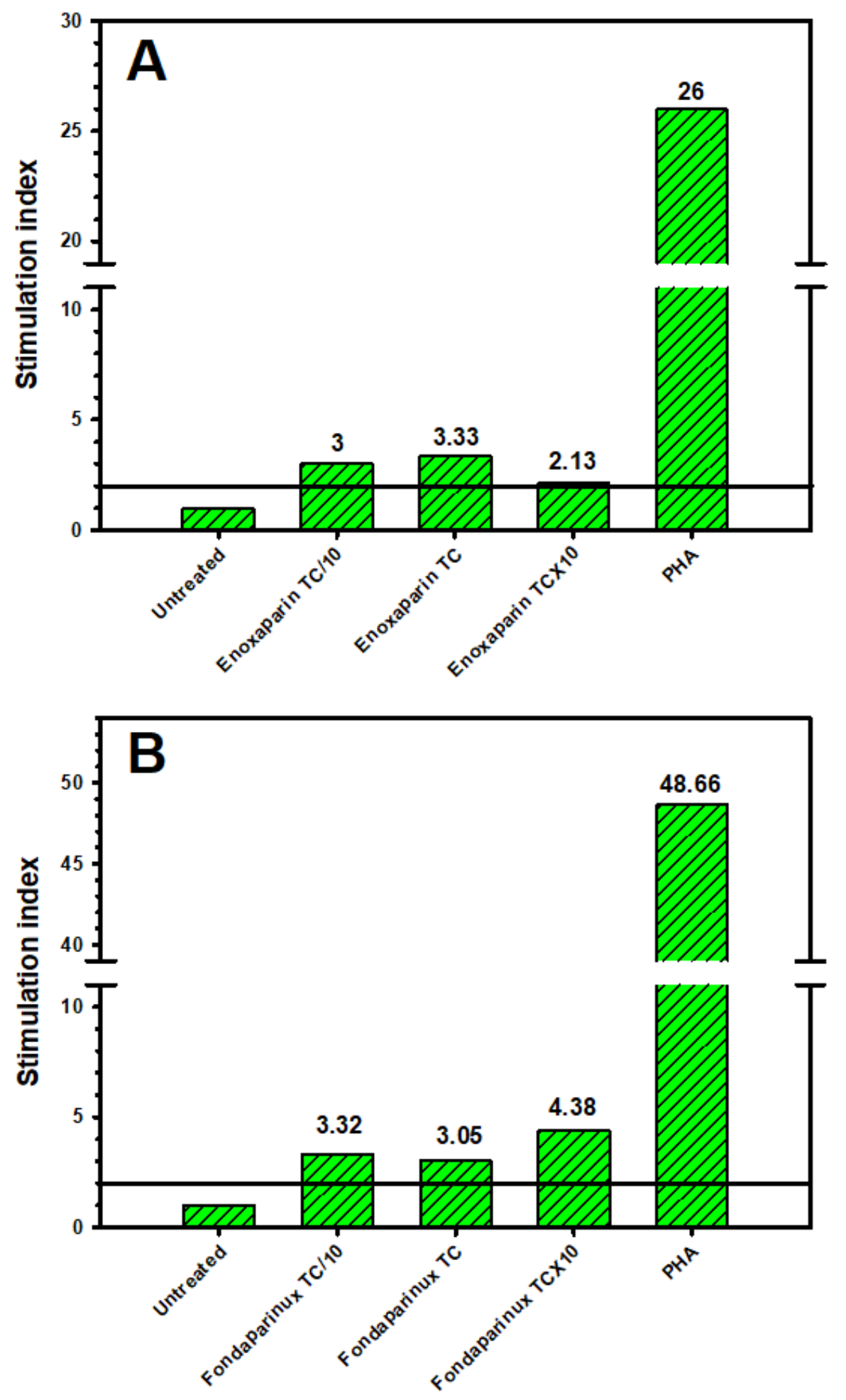

Figure 1

LPT results for enoxaparin (Panel A) and fondaparinux (Panel B). Lymphocyte micro-cultures were exposed to the culprit drugs at therapeutic concentration (TC), TC/10 and TCx 10 , respectively. The test was consistently positive (stimulation index $\geq 2$ ), for all three concentrations for both drugs. Lymphocyte response to the mitogen phytohemagglutinin-M (PHA) was openly valid. 